\title{
Menguduh Data Saham Yahoo Finance Menggunakan YahooFinanceAPI
}

\author{
Andrea Stevens Karnyoto \\ Program Studi Teknik Informatika, Fakultas Teknik, Universitas Kristen \\ Indonesia Toraja \\ andre@ukitoraja.ac.id
}

\begin{abstract}
Abstrak
Dalam hal melakukan prediksi bursa saham, pengumpulan data harga saham terdahulu sangat penting. Oleh sebab itu peneliti melakukan percobaan untuk mengunduh data-data tersebut menggunakan YahooFinanceAPI dan menyimpannya kedalam MySQL database. Proses penyimpanan data ini menggunakan bahasa pemrograman PHP karena bahasa pemrograman tersebut merupakan bahasa yang banyak digunakan. API yang digunakan dapat ditemukan pada situs Github. Hasil yang didapatkan saat menjalankan aplikasi ini adalah rentetan data perusahaan Indonesia yang terdfatar pada Bursa Efek Indonesia.
\end{abstract}

Keywords: Data Stok Saham, Yahoo Finance, YahooFinanceAPI, MySQL

\section{Pendahuluan}

Pada sektor keuangan, harga pasar saham dan trennya paling mudah berubah. Hal ini cenderung menjadi titik pusat dari beberapa penelitian penting yang bertujuan menangkap ketidakpastian dan mengantisipasi langkah selanjutnya. Data historis yang dihasilkan oleh pasar saham sangat besar [4]. Sentimen berkaitan dengan perasaan, sikap, emosi, dan pendapat [6]. Namun, untuk beberapa aplikasi, polanya tampak persisten atau bahkan deterministik selama beberapa tahun. Bagi yang lain, statistik yang memadai dapat dikumpulkan dalam waktu singkat, sehingga prediksi yang akurat dapat dilakukan setiap jam atau bahkan pada skala waktu yang lebih pendek [5]. Teknologi memungkinkan untuk mempermudah masyarakat dalam mengambil keputusan [2]. Metode pengambilan data dapat dilakukan langsung pada kode sumbernya [1]. Agar dapat diprediksi dengan menggunakan aplikasi maka dibutuhkan sebuah metode yang mudah untuk dijalan kan dan tidak memberatkan proses kerja komputer.

Pada penelitian ini, peneliti menggunakan Yahoo Finance sebagai sumber data dan PHP sebagai bahasa pemrograman untuk memproses data saham dari Yahoo Finance dan dimasukkan pada mesin database MySQL. PHP merupakan bahasa pemrograman yang populer untuk membangun aplikasi web base sehingga sangat mudah mendapatkan referensi. MySQL adalah mesin database yang sangat mudah digunakan, gratis, dan sangat populer dikalangan pengembang perangkat lunak.

\section{Metode Penelitian}

Langkah-langkah yang dilakukan dalam penelitian ini adalah dengan mengobservasi tautan yang dapat diakses untuk mendapatkan data saham yang diinginkan. Data saham yang akan dipindahkan dari Yahoo Finance adalah field Open, Close, High, Low, Adjective Close, dan Volume. Frekuensi pengambilan data dilakukan per hari.

Kali pertama melakukan pengunduhan adalah dengan cara menentukan tanggal data awal dan tanggal data akhir yang akan diunduh. Proses pada hari-hari berikutnya adalah 
dengan cara menguduh hari yang sementara berjalan. Dengan demikian maka awal pengunduhan data akan lebih lama dibandingkan dengan penguduhan data pada hari-hari berikutnya.

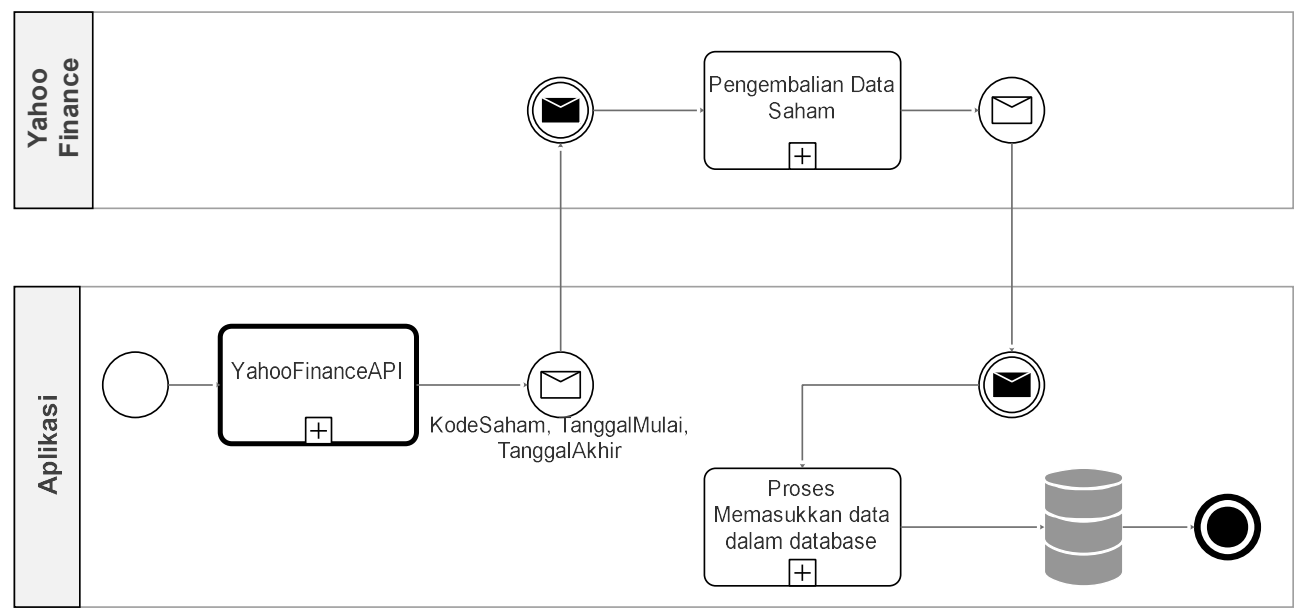

Gambar 1. Proses Bisnis Aplikasi Penunduhan Data Yahoo Finance

Pada gambar 1 dapat dilihat bahwa pengunduhan menggunakan YahooFinanceAPI yang telah kami unduh dari Gihub. YahooFinanceAPI adalah API yang telah dikembangkan untuk melakukan proses pengunduhan data Yahoo Finance. YahooFinanceAPI hanya sebagai sarana penghubung antara komputer kami dengan server Yahoo, masih harus dikembangkan perangkat lunak menggunakan PHP agar proses pengunduhan berjalan dengan baik dan normal. Parameter permintaan data yaitu kodesaham, tanggal awal, dan tanggal akhir. Proses yang berjalan pada server Yahoo adalah pengiriman data yang dibutuhkan untuk kembali ke aplikasi, lalu pada aplikasi melakukan perekaman data kedalam database MySQL.

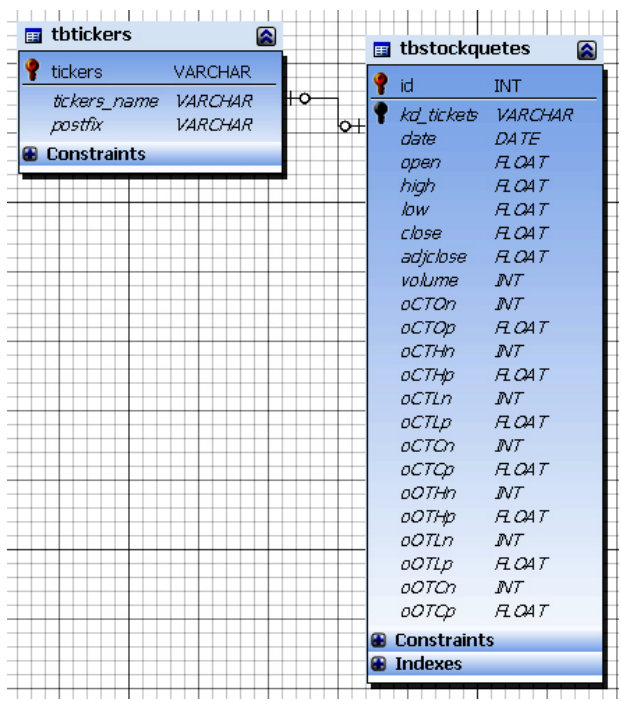

Gambar 2. Koneksi Tabel pada Database

Gambar 2 menunjukkan bahwa untuk mengunduh data dari YahooFinance hanya dibutuhkan dua tabel yaitu tabel tbtickers yang menyimpan seluruh daftar nama 
perusahaan yang ada pada bursa saham indoneisa dan tabel tbstocksquetes yang digunakan untuk menyimpan data-data poin dari saham.

\section{Hasil dan Pembahasan}

Dari data yang kami dapatkan terdapat 555 perusahaan yang terdaftar pada bursa saham Indonesia.

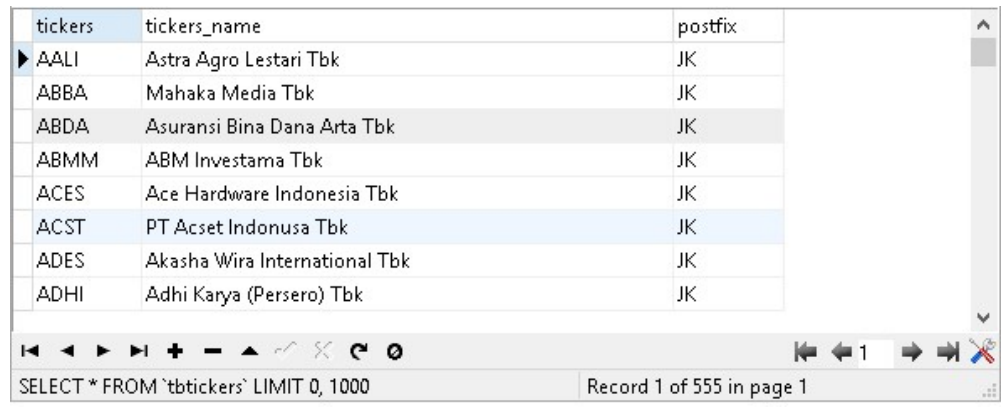

Gambar 3. Daftar Nama Perusahaan yang Terdaftar Bursa Efek Indonesia

Gambar 3 memperlihatkan daftar nama perusahaan, data ini kami dapatkan dari web resmi Bursa Efek Indonesia. Kode tickers tersebut yang akan menjadi dasar pengiriman parameter ke server Yahoo Finance. Karena pada Yahoo Finance terdapat banyak Bursa maka harus ditambahkan kode Postfix JK tiap kode tickersnya.

Untuk melakukan proses unduh data maka yang harus dilakukan adalah dengan membuat program aplikasi sederhana dengan bahasa pemrograman PHP.

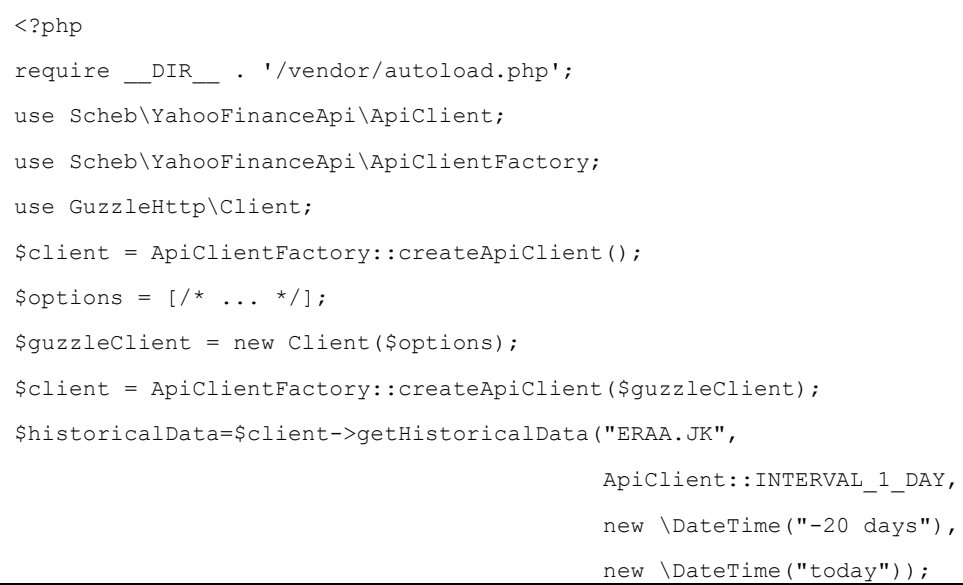

Listing 1. Cara Pengunduhan Data dari Yahoo Finance

Dari listing program 1 dapat dilihat cara mengunduh data 20 hari terakhir, yaitu pada variabel \$historicalData. Object \$historicalData dibuat berdasarkan klas ApiClientFactory::createApiClient(\$guzzleClient). Untuk kode saham nya ditambahkahkan titik(.) dan kode postfix yaitu JK. Contoh diatas dituliskan "ERAA.JK" untuk perusahaan PT. Erajaya Swasembada TBK.

Hasil dari aplikasi tersebut adalah rententan record pada tabel tbstockquetes. Pada penelitian ini, kami hanya meperlihatkan 20 record terakhir dari hasil unduh data tersebut. 


\begin{tabular}{|r|l|r|r|r|r|r|}
\hline Id & kd_tickers & \multicolumn{1}{c|}{ date } & \multicolumn{1}{c|}{ open } & \multicolumn{1}{c|}{ high } & \multicolumn{1}{l|}{ low } & \multicolumn{1}{c|}{ close } \\
\hline 1 & ERAA & $5 / 4 / 2018$ & 1780 & 1800 & 1695 & 1760 \\
\hline 2 & ERAA & $5 / 3 / 2018$ & 1780 & 1865 & 1735 & 1795 \\
\hline 3 & ERAA & $5 / 2 / 2018$ & 1715 & 2120 & 1685 & 1770 \\
\hline 4 & ERAA & $4 / 30 / 2018$ & 1370 & 1710 & 1370 & 1710 \\
\hline 5 & ERAA & $4 / 27 / 2018$ & 1435 & 1470 & 1370 & 1370 \\
\hline 6 & ERAA & $4 / 26 / 2018$ & 1425 & 1540 & 1370 & 1420 \\
\hline 7 & ERAA & $4 / 25 / 2018$ & 1390 & 1550 & 1360 & 1420 \\
\hline 8 & ERAA & $4 / 24 / 2018$ & 1325 & 1440 & 1310 & 1375 \\
\hline 9 & ERAA & $4 / 23 / 2018$ & 1220 & 1320 & 1215 & 1320 \\
\hline 10 & ERAA & $4 / 20 / 2018$ & 1230 & 1230 & 1200 & 1205 \\
\hline 11 & ERAA & $4 / 19 / 2018$ & 1255 & 1275 & 1230 & 1235 \\
\hline 12 & ERAA & $4 / 18 / 2018$ & 1275 & 1275 & 1240 & 1255 \\
\hline 13 & ERAA & $4 / 17 / 2018$ & 1290 & 1300 & 1270 & 1275 \\
\hline 14 & ERAA & $4 / 16 / 2018$ & 1300 & 1305 & 1280 & 1295 \\
\hline 15 & ERAA & $4 / 13 / 2018$ & 1300 & 1305 & 1280 & 1290 \\
\hline 16 & ERAA & $4 / 12 / 2018$ & 1270 & 1285 & 1240 & 1280 \\
\hline 17 & ERAA & $4 / 11 / 2018$ & 1275 & 1280 & 1250 & 1255 \\
\hline 18 & ERAA & $4 / 10 / 2018$ & 1225 & 1265 & 1200 & 1265 \\
\hline
\end{tabular}

Tabel 1. Hasil proses aplikasi dalam tabel tbstockquetes

Tabel 1 memperlihatkan tabel tbstockquetes yang merupakan hasil pengunduhan dari perusahaan PT. Erajaya Swasembada TBK dengang kode saham "ERAA.JK".

\section{Kesimpulan}

Dari penelitian pengembangan aplikasi ini, dilihat bahwa untuk mendapatkan data harga saham dapat diperoleh dengan mudah. API yang dibuat dan disebarkan pada situs github sangat membantu dalam melakukan proses ini. Peneliti menggunakan pemrograman PHP yang secara umum telah digunakan sehingga dapat dengan mudah untuk diperbaharui dan dimanfaatkan oleh masyarakat. Untuk mendapatkan 20 data saham terakhir dibutuhkan waktu sekitar 1 detik.

\section{Daftar Pustaka}

[1] A. S. Karnyoto and M. Limpo, "Web Tags Formatting with Multilevel Numbering", Information System International Confrence(ISICO), 2013

[2] A. S. Karnyoto et al., "Semantically-Interlinked Based on Rich Site Summary Bank for Sites of Indonesia Online News", International Research Journal of Engineering and Technology (IRJET), vol. 5 issue 1. 2018.

[3] A. Kaushal and P. Chaudary, "News and Events Aware Stock Price Forecasting Technique", 2017 International Conference on Big Data, IoT and Data Science (BID).,(2007)

[4] M. H"ahnel et al., "Extending the Cutting Stock Problem for Consolidating Services with Stochastic Workloads", IEE2018 (2018)

[5] P. Chakraborty et al, "Predicting Stock Movement using Sentiment Aanalysis of Twitter Feed", IEEE 2017. 